\title{
NÚMERO DE FORAMINAS Y FORMA DE FORAMEN MAYOR PRESENTES EN LA RAIZ MESIO VESTIBULAR DEL PRIMER MOLAR SUPERIOR - IN VITRO.
}

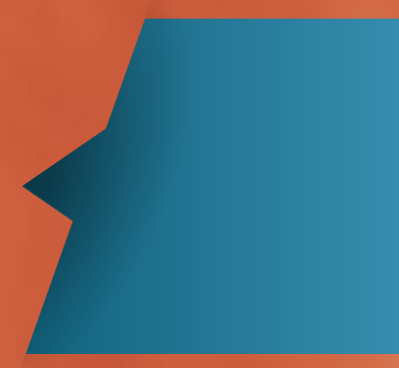

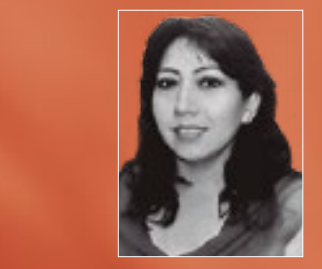

Dra. Erika Espinosa Directora - Postgrado Endodoncia Universidad Central Del Ecuador

\section{RESUMEN}

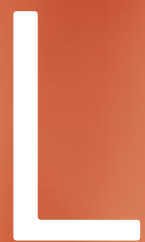

Las diferentes variaciones anatómicas de la raíz mesio vestibular del primer molar superior ha sido objeto de algunos estudios. El conocimiento de ésta y sus diferentes variaciones principalmente en el ápice podrían determinar el éxito en la terapia endodóntica, por lo que determinar el número de foraminas y forma de foramen de la raíz mesio vestibular (MV) es el principal objetivo de este estudio.

En el mismo se utilizó una muestra de 40 primeros molares superiores humanos extraídos de pacientes de la población ecuatoriana, y observada la raíz mesio vestibular al estereomicroscopio. Se obtuvo como resultados un elevado porcentaje de dos a tres foraminas y la forma oval de foramen mayor es la más frecuente.(UCE-PG. Endodoncia; 2015;1-6)

Palabras claves: raíz mesio vestibular, foramen mayor, foraminas.

\section{INTRODUCCIóN}

El conocimiento de la anatomía interna y la morfología de las piezas dentarias, ha permitido una adecuada preparación y limpieza del conducto radicular. Varios métodos han sido empleados para la identificación y análisis de la forma y número de los forámenes apicales presentes en la raíz de las diferentes piezas dentales, lo que ha ayudado en el éxito de la terapia endodóntica.

La variedad anatómica del sistema de conductos radiculares constituye un verdadero reto para el profesional, por lo que el clínico debe conocer a detalle las posibles alteracio-

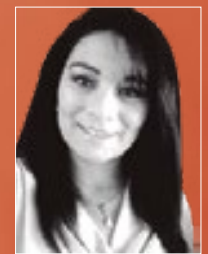

Odont. Daniela Puebla E. Posgrado de Endodoncia Facultad de Odontología Universidad Central del Ecuador

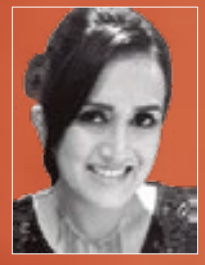

Odont. Diana Valarezo C. Posgrado de Endodoncia Facultad de Odontología Universidad Central del Ecuador nes que pueden presentarse en el periápice; y los diferentes métodos de ayuda diagnóstica convencional (como el uso de radiografía periapical, radiovisiografía, y localizador de ápice) no permiten conocer con exactitud a lo que el clínico se enfrenta. (1)

Canalda define: "al foramen como el orificio apical que corresponde a la terminación del conducto radicular, y a las Foraminas, como los diferentes orificios que se encuentran alrededor del foramen y que permiten la desembocadura de conductillos que forman el delta apical". En Concordancia con esto Fisher en 1912 demostró que el conducto radicular no termina en un solo foramen, sino que puede ramificarse presentado varias foraminas (2) que ocurren por una falla de la Vaina Epitelial de Hertwig en etapas embrionarias. Dichos estudios concuerdan que esta falla se produce principalmente en las raíces de premolares y molares, reportandose en un caso la presencia de hasta 16 foraminas dando el aspecto de criba a la raiz. (1)(3) (4).

Esta variabilidad anatómica es en muchas ocasiones una de las causas del fracaso en el terapia endodóntica, debido a la persistencia de microorganismos en estas zonas y su estrecha comunicación con los tejidos periodontales. Esta microbiota frecuentemente se compone de especies Gram positivas y anaerobias facultativas. Sin embargo Murad et al. manifestó que cuando la lesión periapical persiste posterior a la terapia endodóntica existe un predominio de bacterias Gram negativas. (5)

La forma del foramen mayor es controversial, y se encuentra escasa literatura, sin embargo en el 2004 Marroquín et al. en su estudio concluyeron que la forma más común observada del foramen era oval (70\%). (6). 

superior es una de las piezas dentaes que con mayor frecuencia recibe terapia endodontica, "posiblemente la más tratada y la menos entendida de los dientes posteriores" (7), siendo la raiz mesiovestibular la que presena mas dificultad para el tratamienanatómica. El objetivo principal de este estudio
es determinar el número de foraminas presentes en la ráíz mesio vestibular del primer molar superior y forma predominante del foramen apical en piezas dentales extraídas a través del estéreomicroscopio.

\section{MATERIALES}

Y MÉTODOS

Para este estudio se recolectaron por los estudiantes de postgrado de Endodoncia de la Universidad Centra superiores de humanos extraídos po diversas razones. Como criterios de inclusión se consideró que las piezas dentales no debian tener tratamiento endodóntico previo y su ápice completamente formado. Se excluyo también, dientes primarios y raíces que presentaban reabsorcion radicular. Edad y sexo desconocidos.

Las piezas seleccionadas fueron cuitejido óseo y tártaro dental. Posteriormente sumergidas en hipoclorito de sodio al $5.25 \%$ por 24 horas y esterilizadas en autoclave y con una lima \# 10 (Dentsply Mailleefer) se permeabilizo los conductos de la raíz mesio vestibular.

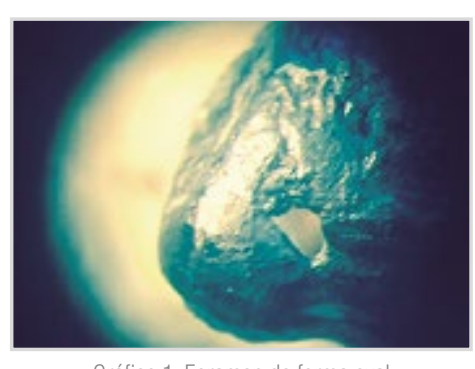

El análisis de la raíz mesio vestibular de los primeros molares superiores se realizó con estéreo microscopio (ma$52 X$ en el magnicacion de $32 X$ la Facultad de Odontología de la Unversidad Central del Ecuador.

Las muestras fueron divididas en 2 grupos de 20 piezas dentarias y valoradas por dos observadores en diferentes momentos. Los valores obtendos a $32 X$ en estereomicroscopio se utilizaron para registrar el número de foraminas encontradas en la raíz mesio vestibular del primer molar superior. Para observar la forma del aguie ro apical se utilizó una magnificación de $52 X$, clasificándolos como redonda y oval.

Los ápices anatómicos de cada una de las piezas dentarias analizadas los pintó con tinta negra, para poder observar con mayor nitidéz la forma del foramen. (Grático 1 y

\section{RESULTADOS}

Un total de 40 raíces mesio vestibulares de primeros molares superiores fueron observadas al estereomicroscopio, de las cuales el $60 \%$ presentaron un solo foramen apical correspondiente a 24 piezas dentarias, $32,5 \%$ (13 piezas dentarias) presentaron 2 forámenes apicales y el 7,5\% (3 piez dentarass) tuvieron 3 forámenes apicales.(Ver tabla 1 A.y 1 .

El $80 \%$ de la muestra presento un foramen apical de forma oval equiva lente a 32 piezas dentarias y el $20 \%$ restante de la muestra presentó forma redonda (8 piezas dentarias) (Ver tabla 2 у 2в.)

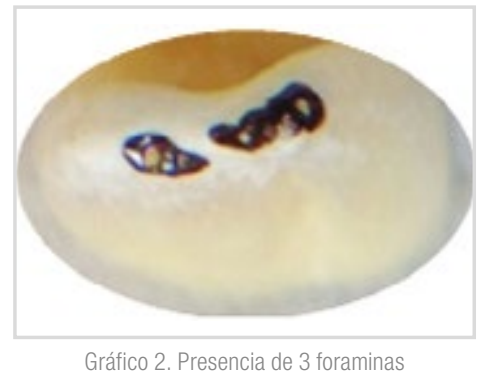

\section{TABLA 1}

A. De un total de 40 piezas dentarias estudiadas se demostró que 24 presentaron un solo forámen, 13 dos foramenes $y$ tres raices tuvieron tres do en porcentajes, $60 \%$ mayor prevalencia de 1 solo foramen apical $32,5 \%$ presencia de 2 forámenes apicales y 7,5\% con 3 foramenes, en un total de 40 raices mesio vestibulares de primeros molares superiores.

\section{| Tabla 1A}

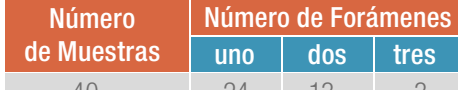

\section{| Tabla 1B}

№ de Foramen y Foraminas

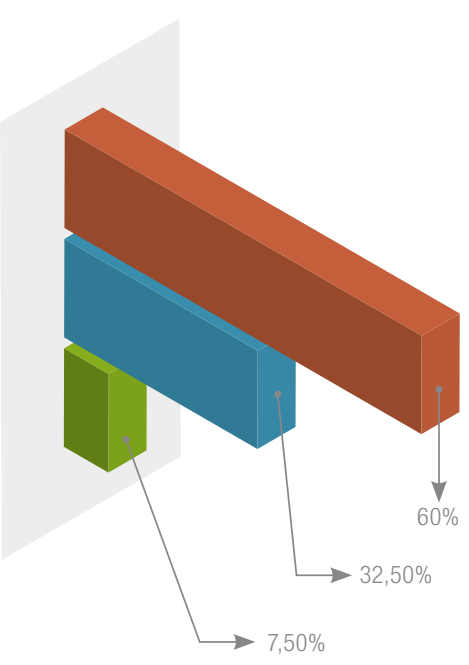

\section{DISCUSIÓN}

Tabla 2A

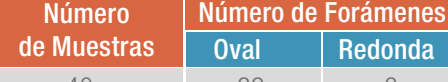

Tabla 2B

Forma Foramen

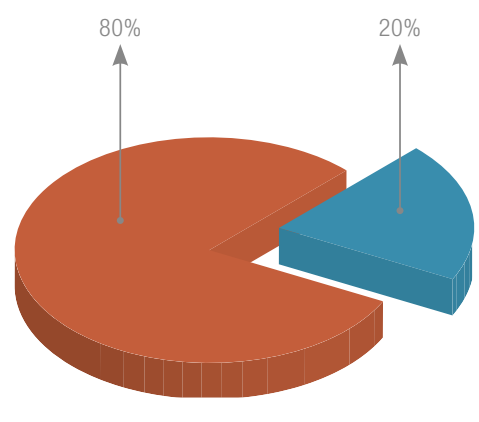

ReDONDA
Los primeros molares superiores son frecuentemente investigados a causa de su anatomía y morfología adicular compleja", un estudio publicado recientemente de la población brasileña concuerda que la raíz mesio vestibular del primer molar superior es la que más variación en su sistema de canales presenta en comparación con las otras raíces de esta misma pieza dentaria. (8) La morfología de raíces y canales varía entre las diferentes razas, (9) de ahí la importancia de esta investigación realizada la población ecuatoriana.

Con gran frecuencia es posible identificar la presencia de múltiples forámenes accesorios, lo que sugiere la extensa ramificación del conducto radicular en el ápice. (9) Sin embargo en una revisión literaria del 2006, con una recopilación de 34 estudios y con un total de 8399 dientes estudiados Cleghorn et al. manifiestan la presencia de un solo foramen apical en el $61,6 \%$ de los casos mientras que dos agujeros apicales separados taban presentes en un 38,3\%. (10

ron 3 forámenes apicales, al evalua úmero similar de piezas denta-

Algunas investigaciones identificaron bacterias en las ramificaciones de canal radicular, siendo posiblemente una causa de fracaso endodóntico y atribuyéndole a que la zona crític para el tratamiento radicular son los $3 \mathrm{~mm}$ apicales, en donde están prelo que la presencia de bacterias en os conductos radiculares desempenan un papel importante en la persistencia 0 aparición de lesiones de periodontitis apical después de un tratamiento de conducto (13), siendo de gran importancia una adecuada Iimpieza e irrigación de estas $70-$ nas en las que no se puede acceder con instrumentación y difícilmente s observa con tecnicas radiográficas convencionales, el detallado conocimiento de la anatomia de estos 3mm apicales nos ayudará a obtener medóntica.

El $40 \%$ de la muestra estudiada representa la presencia de 20 más foraminas en la raiz mesio vestibula de primeros molares superiores, es$60 \%$ de las raices analizadas presentaron un solo foramen apical, e $32,5 \%$ presentaron 2 forámenes apiacs y el 7,5\% tuvieron 3 forámenes apicales.

Somma F. et. al. Analizaron 30 primeros molares superiores y encontraron la presencia de un solo foramen apical en el $37 \%$ de las muestras, dos agujeros apicales en el $23 \%$ de los casos y tres o más agujeros apicales separados en el $40 \%$ de las muestras, dichos resultados no coinciden con lo estudiado en primeros molares superiores de la población ecuatoriana, en donde el $60 \%$ de las raices analizadas presentaron un solo foramen apical, el 32,5\% presentaron 2 forámenes apicales y el 7,5\% tuvie- a ealizar el tratamiento de conducto de sta pieza dentaria.

La forma del foramen mayor de primeros y segundos molares superiores en la poblacion del Norte de fue en el $81 \%$ de los casos Oval (9). A Igual que lo mostrado por Marroquin et al. en el 2004 en donde se analizo 260 primeros molares superiores y se observo la forma del foramen en MB1 y MB2, concluyendo que la forma oval se presento en $72,97 \%$ para MB1 y $68,11 \%$ para MB2, y de forma redonda en el $23,78 \%$ y $24,87 \%$ respectivamente. (6) cos con nuestro estudio en donde 
$80 \%$ de las muestras presentó forma oval y un $20 \%$ de forma redondeada en su foramen mayor.

Sin embargo Martos et al. al valorar la forma del foramen mayor en 222 molares superiores concluyeron que la forma predominante en dichas muestras es redonda, en un $67,6 \%$, oval en un $19,4 \%$, asimétrico $7,7 \%$ y semilunar en $5,4 \%$ (14). Estos resultados no coinciden con los descrito en la presente investigación y esta diferencia puede deberse a que Martos et al. realizaron este analisis con microscopio electrónico de barrido (MEB) y el presente estudio fue realizado con estereomicroscopio (EM), la variación de los resultados podrían deberse a que con MEB es posible una mayor magnificación y precisión de las estructuras observadas, mientras que EM únicamente permite una visiòn macro del objeto de estudio.

Es relevante dar a conocer que al realizar este estudio con estereomicroscopio posiblemente no se observó de forma precisa las estructuras dentales investigadas como se lo hubiera podido realizar con MEB. Assumpção et al. Realizo un estudio comparativo entre el MEB y el Microscopio clinico (MC) para poder observar la presencia de foraminas en 50 piezas dentarias (incicivos y caninos) y concluyó que el foramen principal fue detectado en todas las muestras con MC y como MEB. Pero que con el MEB se observo 37 foramenes accesorios y con el MC solo se observaron 17.

Demostrando que el MEB nos ofrece una mejor visualizacion de los objetos estudiados.

\section{CONCLUSIÓN}

Aun con las limitaciones de este estudio se demostró presencia del $\mathbf{4 0 \%}$ de la muestra con dos y tres forámenes en la raíz mesio vestibular del primer molar superior de la población ecuatoriana y en un $\mathbf{8 0} \%$ el foramen mayor de forma oval, por lo que podemos concluir que el conocimiento de la anatomía y morfología de los conductos radiculares es de vital importancia para el éxito del tratamiento endodóntico.

\section{REFERENCIAS BIBLIOGRAFICAS}

1. Cantore G; Berutti E; Castellucci A; MISSED ANATOMY: frequency and clinical impact ;Endodontics Topics; 2009;15;3-31

2. Canalda C; Brau E;Endodoncia, Técnicas Clínicas y bases científicas; Ed. Elsevier España;2006; 2da. edición;pág. 26

3. Weine F. et al; In Remembrance of Franklin S. Weine Canal Configuration in the Mesiobuccal Root of the Maxillary First Molar and Its Endodontic Significance; J. Endod; 2012;38(10); 1305-8.

4. Gutierrez J; Aguayo P; Apical foraminal openings in human teeth. Number and location; Oral Surg Oral Med Oral Pathol Oral Radiol Endod. 1995 Jun;79(6):769-77.

5. Murad et al.Microbial Diversity in Persistent Root Canal Infections Investigated by Checkerboard DNA-DNA Hybridization; J. Endod; 2014;40(7); 899-906.

6. Marroquín B; El-Sayed M; Willershausen-Zonnchen B; Morphology of the Physiological Foramen:I. Maxillary and Mandibular Molars; J.Endod; 2004; 30 (5); 321-28.

7. Schigli A; Agrawal A; Permanent maxillary first molar with single root and single canal: A case report of a rare morphology; J Indian Soc Prevent Dent; 2010; 28 (2); 121-25.

8. Nogueira Leal Silva E. et al; Evaluation of Root Canal Configuration of Maxillary Molars in a Brazilian Population Using Cone-beam Computed Tomographic Imaging: An In Vivo Study; J. Endod; 2014; 40(2); 173-176.

9. Arora S; Tewari; The morphology of the apical foramen in posterior teeth in a North Indian population; Int. Endod. J; 2009; 42; 930-939.

10. Cleghorn B: Christie W: Dong C; Root and Root Canal Morphology of the Human Permanent Maxillary First Molar: A Literature Review; J. Endod;2006; 32 (9); 813-821.

11. Somma F. et al; Clinical article root canal morphology of the mesiobuccal root of maxillary first molars: a micro-computed tomographic analysis; Int. Endod. J; 2009; 42; 165-174.

12. Assumpção T; Bramante C et. al: Avaliação de Foramina Acessórios com o Uso do Microscópio Clínico e Electrónico de Varredura; Rev. Portuguesa de Estomatologia, Medicina Dentária e Cirurgía Maxilofacial; 2009;50(4); 215-219.

13. Siqueira J; Rôças I;Clinical Implications and Microbiology of Bacterial Persistence after Treatment Procedures; J. Endod;2008;34(11);1291-1301.

14. Martos J. et al; Morphologic Analysis of the Root Apex in Human Teeth; J Endod; 2010; 36:(4);664-667. 